\title{
Non-Verbal Communication of German Language in a German Film:
}

\section{A Coffee in Berlin}

\author{
FARHANA FARID \\ ROSLINA MAMAT \\ Universiti Putra Malaysia
}

\begin{abstract}
Non-verbal behaviour is very important in conversations, yet it is not given much attention. Foreign language learners who are not exposed to these pivotal non-verbal communications will find it difficult to recognise it during a conversation which consequently could lead to confusion. In addition, it will also affect the flow of the conversation especially among language learners that have less access to real language situations or native speakers. This article begins with analysing a German language conversation in a German film "A Coffee in Berlin" by Jan Ole Gerster, to detect the non-verbal turntaking signals as well as to interpret the function and purpose of the signals based on the Stenstrom's theory (1994) of turn-taking. This article uses Gesprächsanalytisches Transkriptionssystem 2 (discourse and conversation- analytic transcription 2) or also recognised as GAT 2 by Selting (2009) for the data transcription as it is highly adaptable in transcribing data of German language to detect the non-verbal turn-taking signals in the conversation. Qualitative descriptive is chosen as the method of this study as it is detailed, comprehensive and makes sense to the reader. Using the method and theories stated bring results of the non-verbal turn-taking signals such as gaze, gestures and facial expression which are used in German conversation when yielding, continuing and taking the floor of conversation.
\end{abstract}

Keywords: Non-verbal behaviour, turn-taking, conversation analysis, German language, language learners.

\section{INTRODUCTION}

Non-verbal behaviour is a part of non-verbal communication where thoughts and feelings are sent and received through it (Ambady \& Weisbuch, 2010). It plays an important role in conversation when speakers and listeners are taking turns. According to Koutsombogera, Ammendrup, Vilhijalmsson and Papageorgiou (2011), non-verbal behaviour is applied to ensure the flow of a conversation. Lacking knowledge in non-verbal communication could lead to lacking communication competency. In other words, DeVito and Hecht (1990) describe that non-verbal communication is also known as the messages conveyed other than words (Gregersen, 2007).

Argyle (1988) has listed five primary functions of non-verbal behaviour in human communication which are; to express emotions, to express interpersonal attitudes, to accompany speech in managing cues in conversation, self-presentation of one's personality and rituals (greetings) (Bujalkova \& Zrnikova, 2015). It is significant to be acknowledged by language learners since language does not only consist of grammar, spelling and pronunciation, but also the culture and customs (Ren, 2014). Every language and culture has its way of using non-verbal signals in communication. To some languages, nodding the head can mean 'No' whilst shaking the head means 'Yes', pointing using the index finger is inappropriate and gazing down during communication is considered rude. Hence, it is important for a person who wants to acquire a language to get used to non-verbal signals. 
Discussing the non-verbal behaviour in conversation is also to fill in the gap of communication understanding across different cultures (Adetunji and Koh Phei Sze, 2012).

To be able to use the language efficiently, language learners have to know how to take turns during a conversation. Effects of turn-taking on human's interaction are something to be alerted with, as turn-taking behaviour is significant in controlling the conversation (Hassaskhah, Sabet \& Tarang, 2016). Turn-taking, first investigated by Sacks, Schlegoff and Jefferson in 1974, is also a theory that is widely used to understand the turn-taking organisation within a conversation (Brunett, 2017). Brunett (2017) added that the theory defines turn-taking as the exchange of allocating speaker and listener so that one speaker speaks at a time through the turn-construction unit or possibility of turn-transfer at turn relevant place. According to Sacks, Schegloff and Jefferson, there are turn-taking signals that exist for speakers to hold, take and yield the floor; although they have not discussed any further about it yet, other researchers have focused on quite an amount of different signals which are verbal and non-verbal (Taboada, 2006).

Although Sacks, Schlegoff and Jefferson's (1974) turn-taking theory has been used widely in previous studies, this study has chosen a theory introduced by Anna Brita Stenstrom in 1994 as the theoretical framework since it is considered as relevant to current research. Horak (2013) mentioned that the theory proposed by Stenstrom is easy to learn non-verbal turn-taking signals has not received much attention, especially for German language learners in Malaysia. Non- verbal signals or behaviour mentioned are gaze, gestures and facial expressions which are believed to control the organisation of a conversation (Jokinen, 2009). Described further by Gregersen (2007), gaze, gestures and facial expressions own more divisions, for instance;

a. Gaze: sending and receiving signals, to hold the turn, communicate the nature of the interpersonal relationship.

b. Gesture: illustrators, regulators, emblems and affecting display and highly adaptable and apart from that, is believed to complement the data collected for this study. Corresponding to Stenstrom's theory (1994), turn-taking is divided into three strategies which are; taking the turn, holding the turn and yielding the turn (Anwair, 2017). Taking the turn includes: starting up, taking over and interrupting, whilst holding the turn is to continue talking which involves: filled pause, lexical, repetition and a new start in conversation and lastly yielding the turn: prompting, appealing and giving up (Anwair, 2017).

c. There are a number of studies discussing these signals of turn-taking, but ones pertaining to non-verbal signals are still lacking (Bonaccio, O’Reilly, O'Sullivan \& Chiocchio, 2016; Gregersen, 2007).

d. Facial expressions: signal readiness, smiles and flashes used in greetings, smiles temper a negative message, conspiratorial wink, eyebrows meet to communicate confusion, happiness, sadness, fear, anger, disgust, surprised, face simulates emotion, face intensifies emotion, face neutralises emotion, face de- intensifies emotion, face mask emotion. 
Hence, this study decides to focus on the non-verbal behaviour in the German language conversation as it would fill in the gap of the study since there are insufficient samples and guidelines for German language students here in Malaysia. Giving attention to this and explaining the data would be fruitful for German language learners generally.

As mentioned previously, this study is done in concern of the learners of the German language, especially in Malaysia. This is because the German language has been introduced long ago in Malaysia for many significant reasons, which include the mixed marriage of Malaysians and Germans, for educational purposes; study abroad in Germany and the economic bonds between Malaysia and Germany (Federal Foreign Office, 2019). According to Majtanova (2015), in Malaysia, the German language was introduced initially in the year of 1961 at Goethe Institute Malaysia. Since then, the number of learners has increased and learning German as a foreign language has become a norm especially in Malaysian schools, universities and colleges (Ainol, Isarji \& Mohamad Shari, 2007). It is found that students who are motivated to learn German are those who have background studies in engineering and language field in which they believe will get them better opportunities in future careers. Therefore, studies relating to improve and guide the conversation organisation in the German language will be helpful for the learners as it is a foreign language that is not widely used in Malaysia, but somehow significant.

According to Wanphet (2015) Conversation Analysis (CA) is one of the research tools that could aid researchers in detecting non-verbal signals as CA could show the occurrence of turn- at- talk verbally and non-verbally, how it is produced, delivered and understood by the speakers and listeners in a conversation (Wanphet, 2015). Besides, as cited by Wu (2013), McCarthy (2002) mentions that CA is considered by American discourse analysts as influenced by ethnomethodological tradition, where the smallest units of conversation are described. Not only is CA suitable for studies discussing turn-taking where linguistic and paralinguistic signals are involved, but it is also precise and easily adapted, which makes studies understood without difficulty.

Jeon (2003) cited that Richards, Platt and Weber (1985) has mentioned that the conversation to be analysed is not about the real language at a real setting, but the quality of natural speech instead, hence media through film could aid the learners as it gives a big impact to the society as mentioned by Wibowo (2018). Even in Malaysia, one of the main influences is through media either socially, economically or politically (Maros, Norizan \& Zakaria, 2016).

"A Coffee in Berlin" by Jan Ole Gerster is the film, in which the conversation will be analysed. "A Coffee in Berlin" is a contemporary film that has managed to be nominated for many awards and even won many awards in various categories (IMDB, 2012). Although it was screened in 2012, the movie was screened in black and white, a unique element, which prompted the researchers to select this film. It is believed that black and white cinematography stresses the emotion of the subject in it as, without colours, there would be no distraction which in turn enhances the connection between the viewers and the subject (Geffin, 2014). Echoing Geffin (2014), the film chosen is expected to show more emotions through non-verbal signals.

In 2019, Wunderbar Together listed 'A Coffee in Berlin' in the 50 German films to be celebrated. For information, Wunderbar Together is a comprehensive and collaborative initiative funded by the German Federal Foreign Office and implemented by the GoetheInstitut. In addition, institutions such as Goethe Institute, Penang, University of Oklahoma, 
and Sonoma State University have been screening the film during their German Film Festivals. A Coffee in Berlin or its other name (Oh Boy) is believed as a good film to represent the German people, language and culture and is suitable for German language beginners and film fans (Blankenship \& Twark, 2017). This makes this film apt to be chosen for this study.

A summary of this film: it tells about 'Nico' the main character who is searching for the meaning of life. The film starts and ends with him trying to get a coffee yet obstacles keep coming one after another. Along with the storyline of the film, he has social interaction with people which include his girlfriend, his friends, his new neighbour, his father, a barista, his psychologist, an old lady, a teen boy, police officers, and random people on streets. The social interactions that Nico has in the film with other characters represents how the normal German people deal and have conversations in their daily life and is believed to be suitable for new learners to watch.

Based on the elaboration above, it is significant for non-verbal signals of turn-taking in the German language to be studied. At the same time, findings from this study can be used to aid the learners of German language, specifically in Malaysia, to understand more about how to take turns when speaking in German using non-verbal turn-taking signals utilising German ways. To be precise, the objectives of this study are:

1. To identify the non-verbal turn-taking signals that occur in German language conversation of the film "A Coffee in Berlin" according to Gregersen's (2007) non-verbal behavioural signals.

2. To describe the function and purpose of the non-verbal turn-taking signals in the German language based on Gregersen's (2007) non-verbal behaviour signals and Stenstrom's turntaking theory (1994).

Thus, that concludes the introduction of this study, which covers the base information; terms definitions, problem statement, significance and research objectives of the study, that might be helpful to understand further discussions in the literature review, methodology and the data and results of the study.

\section{LITERATURE REVIEW}

Non-verbal behaviour has been one of the well-known studies which are done especially in enhancing the proficiency of a conversation. Ibrahim, Abdullah, Kasim and Rafik-Galea (2018) managed to go deeper by doing a CA to analyse the management of turn distribution in academic discourse among undergraduate science students in Nigerian Public University. Stenstrom theory (1994) has been applied to study the students' turn-taking management in academic discourses namely during lectures, seminars, oral presentations and verbalising data (Ibrahim, Abdullah, Kasim \& Rafik-Galea, 2018). Followings are the Turn-taking theory proposed by Stenstrom (1994):

a. Taking the turn (to exchange the floor from the current speaker to the next speaker):

- The starting of utterances can show whether the speaker is taking turns to agree, doubts or objects the previous speaker where signals of hesitation could occur. For instance; filled pauses ("em..uh..") and verbal fillers ("well, I mean, you know").

- Direct signals from the current speaker to the next speaker by using the non-verbal behaviour; gaze, gesture, tone and pitch or current speaker calls the next speaker by name or asking questions. 
b. Holding the turn (to carry on talking):

- Speakers who want to hold the floor will tend to use filled pauses, verbal fillers, pauses (to show that the turn is incomplete), lexical repetitions (if.. if if) or initiates a new start to avoid any interruption and to show that they want to continue speaking.

c. Yielding the turn (relinquishing the floor to the next speaker):

- The current speaker is willing to yield the floor by prompting (greetings questions, requests), appealing (using lexical appealers; "all right", "you see") or giving up (giving effective hints which sometimes include the filled pauses).

(Ibrahim, Abdullah, Kasim \& Rafik-Galea, 2018, p. 121)

It is found in the study by Ibrahim, Abdullah, Kasim and Rafik-Galea (2018) that 'appeal' was the strategy used most by students to take a turn and 'gaze' was detected as a strategy for seeking assistance instead of nominating the next speaker, which simultaneously shows that non-verbal signal plays an important role when taking a turn in the conversation.

The complementary study to the topic of this article, a study done by Bujalkova and Zrnikova (2015), chose to pay attention in improving the foreign language's competency by analysing the non-verbal communication of the General Medicine and Dentistry students in Comenius University, Slovakia, in which, the study of German language for special purposes (GSP) has been the main focus. Students who were involved in the GSP course not only were taught the language skills, but also the non-verbal behaviour such as eye contact, facial expression, tone of voice, posture and gesture, timing and sound, to enable them to gain cultural knowledge and sensitivity of the traditions and habits of German native speaker. Students were then evaluated through scientific presentations, as Bujalkova and Zrnikova (2015) believe that through that, students will use a wider range of the non-verbal signals. To evaluate the data, they applied questions proposed by Segal (2015) to define the non-verbal signals involved, precisely:

a. Eye- contact: Is eye contact being made? If so, is it overly intense or just right?

b. Facial expression: What is the face showing? Is it mask-like and inexpressive or emotionally present and filled with interest?

c. The tone of voice: Does the voice project warmth, confidence and interest, or is it strained or impassive.

d. Posture and gesture: Is the body relaxed or stiff and immobile? Are shoulder tense and raised or slightly sloped?

e. Timing: Is there an easy flow of information back and forth? Do non-verbal responses come too quickly or too slowly?

f. Sound: Do you hear sounds that indicate caring or concern?

(Bujalkova \& Zrnikova, 2015, p. 11)

Results of the study indicated that the Slovakian students were not well educated in terms of the non-verbal behaviour, even in their conversation (Bujalkova \& Zrnikova, 2015). They added that although German and Slovakia are not much different in the aspect of the cultural environment, the students sadly could not even manage the elementary level of nonverbal communication. The study also mentioned that it is essential to provide training or give great exposure to non-verbal communication skills in foreign language teaching and learning. 
Addressed in a study by Surkamp (2014), non-verbal communication varies in forms and functions and plays significant roles in teaching foreign language. Other than providing outlines focusing on teaching the non-verbal behaviour to the foreign language learners, approaches mentioned by Surkamp (2014) includes drama activities that encompasses the use of images (like advertising posters), audio-visual material, role-plays, video conferences and real-life meetings during school exchanges. She also stated that students of a foreign language should have the opportunities to develop an awareness of non-verbal behaviour in communication through additional materials combined with drama activities such as film, images and audio texts. Generally, Surkamp (2014) suggests that all foreign language learners should be informed with the potential effects of non-verbal communication whether it is formal/informal conversation, involving intercultural relationships or in literary texts for better competency of the foreign language.

\section{METHODOLOGY}

Qualitative method and the CA approach were used in this study to analyse the data, while the data collected for this study are the conversations which occurred in a German film entitled "A Coffee in Berlin". This study chooses to analyse the German daily conversation as it would be beneficial in influencing learners to apply it in real life situations (Yang, 2008). The film is downloaded and watched several times for the transcribing purpose. Then, several scenes that contain appropriate content for beginners were selected to be analysed. Scenes that were selected are the scenes that contain basic daily conversation between characters which are considered as good samples for German language fans and learners to refer to as role-play scripts in a role-play activity. With basic daily conversation, German language fans and learners would be familiar with the vocabularies from basic topics in normal language books such as 'Greetings', 'Ordering' and 'Self Introduction'. According to Lee (2015), it is important to have linguistic knowledge, sociolinguistics appropriateness and intercultural communication skills for a smoother language practising.

The dialogues of the conversation selected are transcribed using the GAT2 transcript convention as it is believed to transcribe the German language incomprehensible's ways (Selting, Auer, Barth-Weingarten, ....., \& Uhmann, 2011). Transcribed data were also translated in English, hence non- German speakers can also easily understand it. Transcriptions are proofread by native German speakers to validate the quality of the transcriptions in order to get the best and reliable results.

The transcribed data are analysed according to Stenstrom's Theory of turn-taking (1994) and Gregersen's (2007) approach of non-verbal communication. With this theory and approach, the study managed to stay on track to achieve the objectives of the study. To collect the data in a more organised way, the transcriptions are written in a table so the non-verbal turn-taking signals of the conversation can be detected and the purpose of the signals are briefly described. Below is an example of the table (refer Table 1) created for this study which is adapted from Ibraheem (2017): 
Table 1: Transcript table template adapted from Ibraheem (2017)

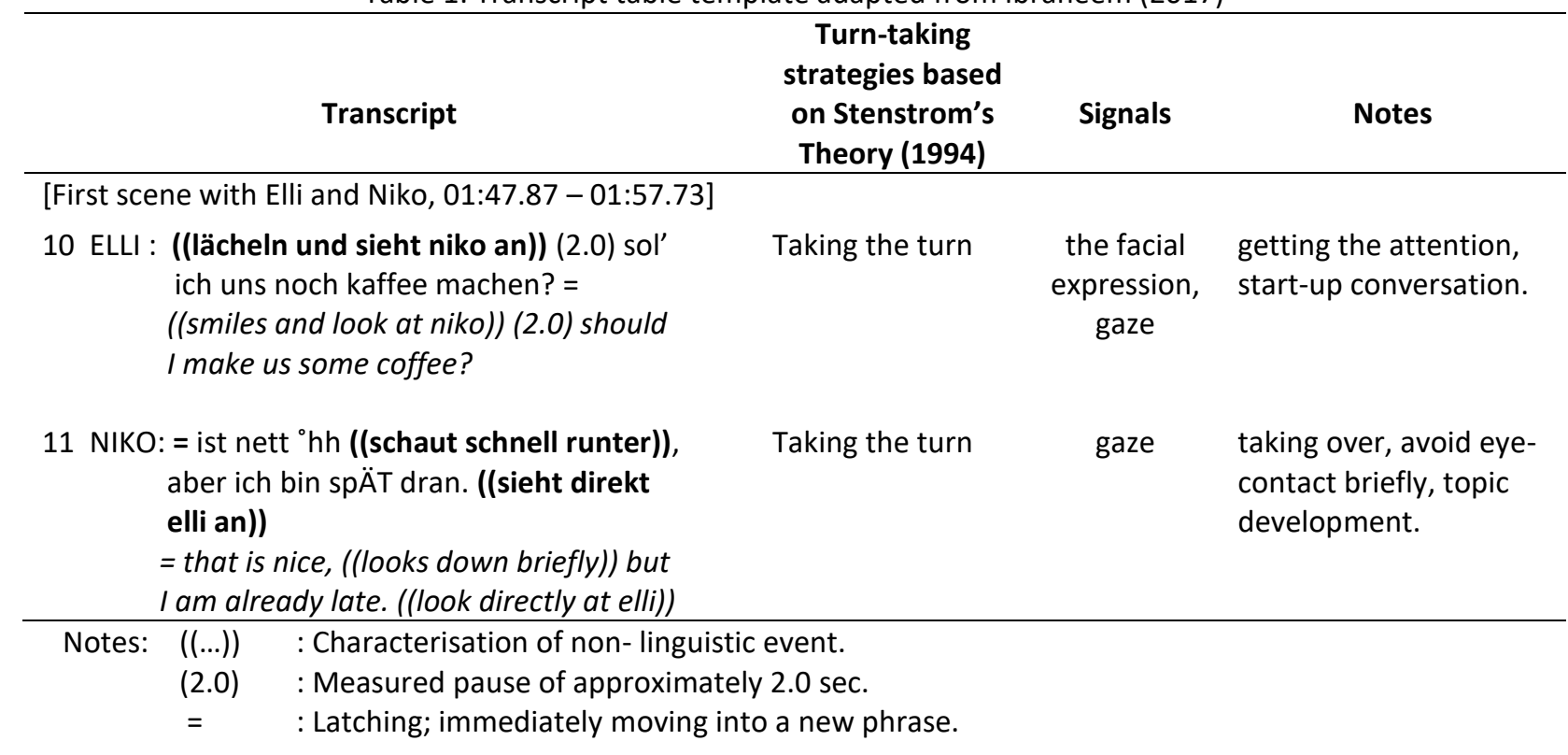

After the data was collected, it was analysed and described in detail to answer the second objective of the study. Further elaboration leads to clearer reasons for the function and purposes of the detected non-verbal signals. The elaborations were also synced to the German cultural perspective.

\section{RESULTS AND DISCUSSION}

After analysing the data collected from the film "A Coffee in Berlin", this study found that all three strategies according to Stenstrom (1994) turn-taking theory; yielding, taking and holding the turn, are involved in the conversations of the film. Since this study focuses on the non-verbal aspects of turn-taking, the data analysis is based on the non-verbal signals of turntaking only.

\section{a. Yielding The Turn Strategy}

Yielding the turn strategy for non-verbal turn-taking signal occurs the most and it happens when the speaker is giving a signal to gain response from the next speaker by using gaze, gesture and facial expressions. This is in line with Stenstrom (1994) who said that yielding the turn is when the speaker appeals to gain a reply from the next speaker (Anwair, 2016). In the film, mutual gaze has been one of the signals for yielding the turn strategy, which is majorly used by the speakers. As stated by Zeki (2009), speakers will tend to make direct eye contact whenever they are indicating that they are talking to the listener or whenever they expect contribution in the conversation from the next speaker.

Kavalchuk (2012) also described that prolonged mutual gaze is accepted within German people, which could vary in other cultures. However, in this study, some of it does not come along with the direct eye contact only, it was also accompanied by the gesture of tilting head, which is a gesture that is meant to connect or link with the next speaker (Debras \& Cienki, 2012). For instance, as can be seen in Extract 1: 
Extract 1 ((Elli and Niko))

01 ELLI : du gehst schon? (---) ((sieht niko direkt an und leicht kopfneigen)) you are going already? ((look directly at niko and slightly tilt head))

02 NIKO: ((sieht elly an)) uh (---) ja, ich muss los. ((look at elly)) uh.. yes, I have to go.

03 ELLI : (--) so früh? so early?

In Extract 1, it shows that Elly as the first speaker is using gaze and gesture as yielding the turn signal by looking directly into Niko's eyes and tilting her head a little bit to let Niko know that she is talking to him and also transferring the conversation floor to him. When Niko responded by looking back directly into Elly's eyes, it shows that he received the signal given by Elly. This is also related culturally as Kavalchuk (2012) mentions that looking directly into one's eyes is to show the seriousness or full concentration during the conversation in Germany. Nevertheless, eye-gaze needs to come along with the head tilt gesture so yielding the turn strategy would be more visible to the next speaker (Jokinen, Yamamoto \& Nishida, 2010). Similar to the sample conversation in Extract 2, where the barista looks directly into Niko's eyes and tilts her head to gain attention from Niko to get a prompt response from him.

\section{Extract 2 ((Niko and the barista))}

104 BAR : $\quad$ was ist für einer? ((sieht niko an und kopfneigen)) (---) what kind of coffee?((look at niko and tilt head))

105 NIKO: ganz normalen kaffee.= just the normal coffee.

106 BAR : =wollen sie was neues probieren? do you want to try something new?

Other than that, this study found out that hand gesture is another non-verbal signal of yielding the turn strategy. Hand gesture as explained by Krauss, Chen and Chawla (1996) is a conversational tool that is assumed to convey semantic information which is the contribution of the utterances of intended meaning (Grice, 1969; Searle, 1969). In the film, characters have been using deictic hand gestures to aid or guide the listener during the conversation as can be seen in Extract 3:

Extract 3 ((Matze, Niko and Julika, in the restaurant))

261 MATZE: =mann stört nicht, komm setz sich, ((hand zeigt den stuhl))= nobody is interrupting, come have a seat, ((hand showing the chair))

263 NIKO: =kein problem. ((nimmt den stuhl)) no problem. ((take the chair))

264 JULIKA: danke. (---)

Thanks

Matze uses his hand gesture to guide Julika as the listener and at the same time the hand gesture works as a signal for Julika and Niko to take the conversation floor, where Niko quickly responds "no problem" and followed by Julika's reply, "thanks". Similar signals are also 
used by characters in the film whenever they try to introduce someone to others. For instance, as shown in Extract 4 and Extract 5 below:
Extract 4 ((Matze Niko and Phillips (P), at Phillips house))
340 MATZE: = das ist mein kumpel, ((sieht niko and und hand zeigt zu
Niko)) [ Niko ],
342 NIKO: [kopfnicken]
nod head
341 P: $\quad$ hallo [ ((handschutteln mit niko)) ]. Philipp Rauch ist schön es zu sehen (---)
hello, ((shake hands with niko)). Phillip Rauch, it is nice to meet you

Extract 5 ((Niko and his father (Vater) at the golf field))

497 VATER: $\quad$ schlechten menschen gehts immer gut. (---) niki, das ist

Schneider ((sieht schneider an und hand zeigt zu schneider)), meine neuer assistent. schneider, niki mein lieblingsohn.

((sieht niko an und hand zeigt zu niko)) = bad people are always fine.. niki, this is Schneider (llook at

Niko and hand show to schneider)), my new assistant. Schneider, this is Niki, my lovely son ((look at Niko and hand shows to Nikoll)

$500 \quad$ NIKO: $\quad=$ sein einziger. ((sieht an schneider)) his only.((look at schneider))

501 VATER: =sei dir da nicht so: sicher. ((lachen und sieht schneider an)) don't be so sure about that ((laugh and look at schneider))

Whenever the characters introduce someone to others, they tend to use the deictic hand gesture like in Extract 4: Matze points his hand to Niko to introduce Niko to Phillip, while in Extract 5: Niko's father does the deictic hand gesture to introduce Niko to Schneider, his assistant. This deictic hand gesture appears to be common across cultures especially in European countries, yet still could vary in other countries, for instance like in Central America; pointing with the lips (Abner, Cooperrider \& Goldin-Meadow, 2015).

\section{b. Holding The Turn Strategy}

Next strategy found is holding the turn strategy. As previously, it is said that German people tend to do mutual gaze when having conversation especially when they are yielding the conversation floor to the next speaker. However, the gaze differs when they want to hold the floor and continue talking. The gaze signal found for holding the turning purpose during the conversation in this study is by gazing down briefly. The characters in the film tend to look down to buy time and continue speaking afterwards. For example, in Extract 6 : 


\section{Extract 6 ((Elli and Niko))}

10 ELLI:

11 NIKO:

12 ELLI: ((lächeln und sieht niko an)) (2.0) sol' ich uns noch kaffee machen? =

((smiles and look at niko)) .. should I make us some coffee?

$=$ ist nett ${ }^{\circ} \mathrm{hh}$ ((sieht schnell runter)), aber ich bin spÄT dran.

((sieht direkt elli an))

$=$ that is nice, ((looks down briefly)) but I am already late.

((look directly at elli))

was ist mit heute abend? =

what about tonight?

It is seen in Extract 6 that Niko is replying to Elli's question, but then he gazed down to buy some time and continue the conversation directly. After holding the turn, Niko gazed back mutually to yield the turn and gains attention from Elli. It shows that when gazing down, the current speaker is avoiding any interruption from other speakers to show that the current speaker still has more to say and it is their time to control the floor (Ho, Foulsham \& Kingstone, 2015). Still, the gazing down is done only briefly and mutual gaze is further used as the signal of yielding the turn. Several parallel examples are also noticed in the conversation of the film as shown in Extract 7 and Extract 8.

Extract 7 ((Niko and the barista))

108 BAR: [sehen sie] das tageansgebot, es wird der marecinno, gibt es für zwei euro extra mit den schokodonut, oder: den schnecke alles hausgemacht alles bio.

you can look at today's offer, there is marocchino, with two euros extra you will get chocolate doughnut, or the rolls are all handmade and organic.

109 NIKO: ehem (.) ((sieht runter and und kopfschutteln)) ich nimm trotzdem glaub ich nur den kaffee. ((sieht der Barista wieder an))= ehem.. ((look down and shake head)) I think I am just going to take only the coffee ((look back at the barista))

110 BAR: $\quad$ =gut ((kopfnicken)). möchten sie kaffee arabica (.) oder den columbia morning? ((sieht niko an))= good. ((nod)) would you like the arabic coffee or the Columbia morning? ((look at niko))

Extract 8 ((Niko and Julika, in the restaurant))

270 JULIKA: =erzähl::: was machst du?:: studierst [du?] ((sieht niko an))= tell me.. what are you doing, are you studying? ((look at niko))

271 NIKO: =[ich?] ehm:: ja ((sieht runter)) (--) ich mach' (-) ja, ((kopfschutteln, hebt die schultern und sieht julika wieder an)) du? erzähl du:: wie: wie geht es dir? = me? ehm.. yes ((look down)) .. I am doing.. yes ((shake head, raise shoulder slightly and me, how are you? 
272 JULIKA: =ehm:: ich weiß garnicht auf du damals mitbekommst, ich bin in der neunten klasse auf ein internet gewechselt. = ehm.. I don't know what are you up to, I change to online school and am currently in the ninth grade

Both extracts above, Extract 7 and Extract 8 display that Niko, as the current speaker looks down to continue the conversation himself. He continues the conversation by elaborating more of his thoughts, as can be seen in Extract 7; "I think I am just going to take only the coffee'. He is also holding the turn to avoid answering Julika's question by reverting questions to Julika after distracting her by gazing down shortly, as shown in Extract 8: "I am doing.. yes ((shake the head, raise shoulder slightly and me, how are you?'. As mentioned earlier, gazing down is used as a signal to buy the time to hold the turn. Buying the time here means for the current speaker to think of further explanation about the previous statement said or to think of yielding the turn later. However, in the film, the gazing down signal is opposite to German culture, which prefers to have mutual eye contact during the conversation in order to not be considered as general weakness and lack of confidence (Kavalchuk, 2012). It varies with the Malaysian culture as mentioned by Norazlina and Raja Masittah (2012) in which gazing down occurs during conversation due to shyness as the cultural value is filled with politeness.

\section{c. Taking The Turn Strategy}

The third non-verbal turn-taking strategy involved in the conversation of the film is taking the turn strategy. In this film, signals shown are gestures of a handshake. The firm German handshake is a gesture to show gratitude between speakers (Schaefer, 2019) and can be viewed as a signal for taking the turn strategy as it seems like it is done spontaneously and promptly after the first speaker is yielding the turn. For example, as presented in Extract 9:

Extract 9 ((Matze, Niko and Julika, in the restaurant))

\begin{tabular}{|c|c|c|}
\hline 266 & JULIKA: & [hallo], \\
\hline 67 & MATZE: & $\begin{array}{l}\text { hello.. } \\
\text { [hallo], ((handschutteln mit julika)) }\end{array}$ \\
\hline 58 & JULIKA: & $\begin{array}{l}\text { hello.. ((shake hand with julika)) } \\
\text { ooh, ((lachen)) }\end{array}$ \\
\hline & & ooh.. ((laugh)) \\
\hline
\end{tabular}

Extract 10 ((Niko and Phillips (P))

340 MATZE: = das ist mein kumpel, ((sieht niko and und hand zeigt zu)) [niko], this is my friend ((look at niko and hand shows to niko))

341 P: $\quad$ hallo [ ((handschutteln mit niko)) ]. Philipp Rauch ist schön es zu sehen (---) hello, ((shake hands with niko)). Phillip Rauch, it is nice to meet you

342 NIKO: [hai, hallo ((handschutteln und kopfneigen))]. hi, hello ((shake hands and tilt head)) 
As shown in Extract 9, Matze takes the turn by shaking hands firmly with Julika and at the same time, Julika knows that he is welcoming her to join in the conversation. Whilst in Extract 10, it shows that Phillip shook his hand with Niko to introduce himself right after Matze introduced Niko to him. Phillip takes the turn by shaking his hand firmly to break the ice of the meeting. Schaefer (2019) added that a handshake is like a trademark of the Germans even when they have nothing to say, they will shake hands to end the conversation or when leaving. Handshaking also occurs within the Malaysian society with greeting purposes and the hand (right hand) will be pulled in toward the chest) to show sincerity (Shida \& Baharuddin, 2014).

\section{CONCLUSION}

Through the analysis, this article found that there are some non-verbal signals of German conversation that are similar to other cultures, but some are not. German non-verbal signals detected are the direct gaze and head tilt when yielding the floor, looking down briefly when continuing the floor and a firm handshake when taking the floor. These findings would aid the German language learners in understanding German cultural queues and then learn the language effectively.

To conclude, all three strategies are involved and proves that German conversation is quite similar to English conversation (Ibraheem, 2017). Finally, learning a language outside of the native language area is challenging as cultural differences might pose as limitations between learners and the language learned. This article proves that film could be used as the medium for German language learners in Malaysia to be able to recognise the non-verbal signals in German conversation by detecting the turn-taking strategies that occur in the conversation. Further study that can be done too perhaps, is to analyse the verbal signals of discourse in the German conversation so that it can be paired with the non-verbal signals for a better intercultural adaptation and language comprehension. It is hoped that more signals can be pointed out in future studies and more cultural awareness can be shared especially within German language learners in Malaysia.

\section{BIODATA}

Farhana Farid is a Master's student at the Faculty of Modern Languages and Communications, Universiti Putra Malaysia and her field is discourse analysis in the German language. Email: farhanafarid14@gmail.com

Roslina Mamat is an Associate Professor in the Department of Foreign Languages, Faculty of Modern Languages and Communications, Universiti Putra Malaysia. Her field of study is Japanese discourse analysis and Japanese popular culture. Email: linamm@upm.edu.my 


\section{REFERENCES}

Abner, N., Cooperrider, K., \& Goldin-Meadow, S. (2015). Gesture for linguists: A handy primer. Language and Linguistics Compass, 9(11), 437-451.

Adetunji, R. R., \& Sze, K. (2012, November). Understanding non-verbal communication across cultures: A symbolic interactionism approach [conference paper]. i-Come International Conference on Communication and Media 2012, Penang, Malaysia, 1-3 November 2012. https://ssrn.com/abstract $=2178486$

Ainol, M., Isarji, H. S., \& Mohamad, S. N. (2007). A study of the effectiveness of foreign language programs in Malaysia. Proceedings in the 32nd Annual Congress of the Applied Linguistics Association of Australia, Making a difference: Challenges for applied linguistics, University of Wollongong (pp. 1-3).

Ambady, N., \& Weisbuch, M. (2010). Nonverbal behavior. In S. T. Fiske, D. T. Gilbert, \& G. Lindzey (Eds.), Handbook of social psychology (p. 464-497). John Wiley \& Sons. https://doi.org/10.1002/9780470561119.socpsy001013

Anwair, S. (2017). A study of turn taking in extensive reading lecture at English study program of Halu Oleo University. Journal of Teachers of English, 1(1).

Bonaccio, S., O'Reilly, J., O'Sullivan, S. L., \& Chiocchio, F. (2016). Nonverbal behavior and communication in the workplace: A review and an agenda for research. Journal of Management, 42(5), 1044-1074.

Brunett, A. (2017). The organization of turn-taking in fieldwork settings: A case study [Master's Theses and Doctoral Dissertations, Eastern Michigan University, No. 748]. Digital Commons @EMU.https://commons.emich.edu/theses/748

Bujalková, M., \& Zrníková, P. (2015). Nonverbal communication and its importance for the development of foreign language professional competence in medical and dentistry students [conference paper]. Athens: ATINER'S Conference Paper Series (No: EDU2015-1754).

Debras, C., \& Cienki, A. (2012, September). Some uses of head tilts and shoulder shrugs during human interaction, and their relation to stance taking [conference paper]. 2012 International Conference on Privacy, Security, Risk and Trust and 2012 International Conference on Social Computing (pp. 932-937). IEEE.

Federal Foreign Office (2019). Germany and Malaysia: Bilateral relations. German Embassy Kuala Lumpur. https://kuala-lumpur.diplo.de/my-en/themen/politik/-/1509238

Geffin, D. (2014, December 2). Why it's still important to shoot in black and white. Fstoppers. https://fstoppers.com/education/why-its-still-important-shoot-black-and-white48141

Goethe Institute USA. (2019). Wunderbar films: German cinema 101. https://www.goethe.de/ins/us/en/sta/wsh/ver.cfm?fuseaction=events.detail\&event id $=21368362 \&$

Gregersen, T. S. (2007). Language learning beyond words: Incorporating body language into classroom activities. Reflections on English Language Teaching, 6(1), 51-64.

Hassaskhah, J., Sabet, M. K., \& Tarang, M. (2016). Turn taking signals within Iranian context. Journal of Applied Linguistics and Language Research, 3(2), 70-85. https://jallr.com/index.php/JALLR/article/view/275

Ho, S., Foulsham, T., \& Kingstone, A. (2015). Speaking and listening with the eyes: Gaze signalling during dyadic interactions. PloS One, 10(8). 
Horák, J. (2013). Discourse analysis of professional business and professional organizational domains: Based on VOICE corpus [Master's diploma thesis, Masaryk University Faculty of Arts Department of English and American Studies]. Informační Systém Masarykovy Univerzity. https://is.muni.cz/th/xjmt5/diplomka plny text.pdf

Ibraheem, S. J. (2017). Turn-taking strategies in English language teaching (ELT). Dirasat Tarbawiya, 10(40), 291-308.

Ibrahim, B., Abdullah, A. N., Kasim, Z. M., \& Rafik-Galea, S. (2018). Management of turn distribution in academic discourse among undergraduate science students in a Nigerian public university. African Research Review, 12(2), 117-134.

Internet Movie Database, IMDB. (2012). A coffee in berlin. https://www.imdb.com/title/tt1954701/

Jeon, H. J. (2003). Use of film dialogues as a model of natural conversation for developing conversational proficiency [Master thesis, The University of Edinburgh]. ERA Digital Repository. http://hdl.handle.net/1842/486

Jokinen, K. (2009). Nonverbal feedback in interactions. In Tao J., \& Tan T. (Eds.), Affective information processing. Springer. https://doi.org/10.1007/978-1-84800-306-4 13

Jokinen, K., Nishida, M., \& Yamamoto, S. (2010, February). On eye-gaze and turn-taking. EGIHMI '10: Proceedings of the 2010 workshop on Eye gaze in intelligent human machine interaction (pp. 118-123). https://doi.org/10.1145/2002333.2002352

Kastelan, K. (2014). Culture: A coffee in Berlin - A long day's journey into the night. Goethe Institute USA. https://www.goethe.de/ins/us/en/kul/mov/ies/vgf/21333319.html

Kavalchuk, A. (2012). Cross-cultural management: How to do business with Germans - A guide. Deutsche Gesellschaft für Internationale Zusammenarbeit.

Koutsombogera M., Ammendrup S. M., Vilhjálmsson H. H., \& Papageorgiou H. (2011) Nonverbal expressions of turn management in TV interviews: A cross-cultural study between Greek and Icelandic. In Esposito A., Esposito A. M., Martone R., Müller V. C., \& Scarpetta G. (Eds), Toward autonomous, adaptive, and context-aware multimodal interfaces. theoretical and practical issues (Lecture Notes in Computer Science, Vol. 6456). Springer. https://doi.org/10.1007/978-3-642-18184-9 18

Krauss, R. M., Chen, Y., \& Chawla, P. (1996). Nonverbal behavior and nonverbal communication: What do conversational hand gestures tell us? In M. P. Zanna (Ed.), Advances in experimental social psychology (Vol. 28, pp. 389-450). Academic Press. https://doi.org/10.1016/S0065-2601(08)60241-5

Lee, S. (2015). Revisit role-playing activities in foreign language teaching and learning: Remodeling learned cultural identity? Electronic Journal of Foreign Language Teaching, 12(1), 346-359. https://e-flt.nus.edu.sg/wp-content/v12s12015/lee.pdf

Majtanova, M. (2015). Die Rolle der deutschen Sprache für die Gruppenidentität von Deutschen im Ausland: Am Beispiel des Vereinslebens in Kuala Lumpur. Peter Lang $\mathrm{GmbH}$, Internationaler Verlag der Wissenschaften.

Maros, M., Noorizan, N. D. M. M., \& Zakaria, A. A. I. (2016). Code switching as the medium of solidarity in 'Ola Bola'. Jurnal Komunikasi: Malaysian Journal of Communication, 32(2).

Norazlina Mohd Kiram, \& Raja Masittah Raja Ariffin. (2012). Kesantunan berbahasa orang Melayu menerusi gaya pengurusan air muka dalam Saga: Aplikasi teori Ting-Toomey. Jurnal Bahasa, 12(2), 284-300.

Ren, W. (2014). A longitudinal investigation into L2 learners' cognitive processes during study abroad. Applied Linguistics, 35(5), 575-594. 
Schaefer, L. (2019). Eager handshakes and chaotic queues: On German manners. Deutsche Welle: Made for minds. https://www.dw.com/en/eager-handshakes-and-chaoticqueues-on-german-manners/a-47964069

Selting, M., Auer, P., Barth-Weingarten, D., ....., \& Uhmann, S. (2011). A system for transcribing talk-in-interaction: GAT 2. Gesprächsforschung - Online-Zeitschrift Zur Verbalen Interaktion. http://www.gespraechsforschung-online.de/heft2011.html

Shida, I., \& Baharuddin, M. (2014). Amalan hospitaliti dalam masyarakat Melayu tradisional dan sekarang: A case study - Program Inap Desa di Jalan Bharu, Pulau Pinang. https://www.academia.edu/24804288/Amalan_Hospitaliti_Dalam Masyarakat_Mel ayu Tradisional Dan Sekarang Kajian Kes Program Inap Desa Di Jalan Bharu P ulau Pinang

Stenstrom, A. B. (1994). An introduction to spoken interaction. Longman.

Surkamp, C. (2014). Non-verbal communication: Why we need it in foreign language teaching and how we can foster it with drama activities. Scenario, VIII(2), 12-27. https://doi.org/10.33178/scenario.8.2.3

Taboada, M. (2006). Spontaneous and non-spontaneous turn-taking. Pragmatics, 16(2-3), 329-360.

Wanphet, P. (2015). A conversation analysis of EFL teachers' nonverbal gesture in language elicitation stage. ELIA: Estudios de Lingüística Inglesa Aplicada, 15. http://revistas.uned.es/index.php/ELIA/article/view/17999

Wibowo, A. H. (2018). The language of media supporting peace journalism. Jurnal Komunikasi: Malaysian Journal of Communication, 34(3).

$\mathrm{Wu}, \mathrm{Y}$. (2013). Conversation analysis -- A discourse approach to teaching oral English skills. International Education Studies, 6(5), 87-91. http://dx.doi.org/10.5539/ies.v6n5p87

Yang, H. (2008). On teaching strategies in second language acquisition. On teaching strategies in second language acquisition. US-China Education Review, 5(1), 61-67.

Zeki, C. P. (2009). The importance of non-verbal communication in classroom management. Procedia-Social and Behavioral Sciences, 1(1), 1443-1449. 